\title{
MÔ PHỎNG HỆ DÒNG CHẢY VÙNG BIỂN NAM BỘ - VỊNH THÁI LAN
}

\author{
Phạm Xuân Dương \\ Viện Hải dương học-Viện Hàn lâm Khoa học và Công nghệ Việt Nam \\ E-mail: duongpx63@yahoo.com
}

Ngày nhận bài: 15-8-2013

\begin{abstract}
TÓM TÄT: Bài báo trình bày một số kết quả nghiên cứu chế độ dòng chảy ở vùng biển Nam Bộ - vịnh Thái Lan vào mùa gió Đông Bắc (mùa khô) và mùa gió Tây Nam (mùa mưa) bằng mô hình ROMS. Các thông số khi tuợng, thủy triều, bức xạ, bốc hoi được lấy tù bộ số liệu biển toàn cầu có độ phân giải 1/4 độ. Các kết quả nghiên cứu cho thấy, vào mùa gió Đông Bắc, vùng biển Nam Bộ xuất hiện dòng chảy dọc bờ (huớng Đông Bắc xuống Tây Nam) có tần suất cao chảy vào vịnh Thái Lan. Do đặc điểm này mà truờng dòng chảy trong vịnh Thái Lan tại nhiều thời điểm hình thành hoàn lư khép kín ở vùng tù vĩ độ $9^{0}$ trở lên. Vào mùa gió Tây Nam, hiện tuợng này cũng xuất hiện nhung với tần xuất thấp với hướng ngược lại.
\end{abstract}

Tù khóa: Hệ dòng chảy, mùa gió Đông bắc, mùa gió Tây nam, hoàn luu khép kín.

\section{MỞ ĐÀ̀}

Vùng biển nghiên cứu kéo dài từ Bình Thuận (Việt Nam) đến cực Nam Thái Lan (hình 1) là khu vực có địa hình đáy biển khá phức tạp, chia cắt mạnh, mật độ chia cắt dày và độ sâu biển biến đổi từ vài mét đến hàng trăm mét, hình dạng đường bờ biển phức tạp với rất nhiều đảo lớn nhỏ nằm rải rác ở cả phân trung tâm lẫn gần bờ. Đặc điểm này ảnh hưởng tới chế độ hoàn lưu nước nói chung và chế độ dao động mực nước, thủy triều nói riêng [2].

Việc nghiên cứu trường dòng chảy trong vùng biển vùng biển Nam Bộ - vịnh Thái Lan có tầm quan trọng to lớn đến việc nghiên cứu một số lĩnh vực khác như nước trồi, nghề cá, lan truyền chất ô nhiễm, xâm nhập mặn, thoát lũ ra vịnh Thái Lan ... Sự tương tác động lực và môi trường giữa Biển Đông và hệ thống sông Cửu Long cũng đóng vào sự hình thành chế độ thuỷ lực ở khu vực này.

Trong những năm trước đây, một số tác giả trong nước cũng đã tính toán dòng chảy ở khu vực này và trên toàn Biển Đông theo mô hình $3 \mathrm{D}$ và đã xây dựng cấu trúc dòng chảy và sự biến thiên trường nhiệt - muối theo mùa [1]. Nhưng các nghiên cứu này vẫn chưa nói về sự tồn tại và đặc điểm cụ thể của hoàn lưu ở khu vực này như thế nào, đặc biệt ít quan tâm tới sự biến đồi giống và khác theo mùa và các thông tin về hoàn lưu ở các tầng sâu vẫn còn gây nhiều tranh cãi.

Hiện nay ROMS không chỉ có một phiên bản duy nhất, nó được phát triển trong theo chế độ mở của các tổ chức với một loạt các phiễn bản khác nhau. Thông tin trên ROMS là có sẵn tại trang web chính thức cho các nhà phát triển hay người dùng ROMS tại (http://marine.rutgers.edu/po/index.php?model=roms\&page).

Mô hình ROMS sử dụng hệ tọa độ Sigma có ưu điểm là mô phỏng ảnh hưởng của địa hình tới dòng chảy trung thực hơn các mô hình sai phân thông thường. Nhược điểm của nó là xuất hiện sai số số học trong quá trình tính gradient áp suất tại các vị trí có độ dốc lớn mà không thể loại bỏ được hoàn toàn. Nhờ phương 
pháp tái tạo parabolic do Shchepetkin và McWiliams đề xuất $[8,9]$, được sử dụng trong ROMS đã cho phép giảm sai số tới mức có thê chấp nhận được.

\section{PHƯƠNG PHÁP NGHIÊN CÚU}

Hệ phương trình cơ bản của ROMS viết trong tọa độ Đề Các $(\mathrm{x}, \mathrm{y}, \mathrm{z}, \mathrm{t})$ có dạng cơ bản từ (1) đến (7):

Phương trình liên tục

$$
\frac{\partial u}{\partial x}+\frac{\partial v}{\partial y}+\frac{\partial w}{\partial z}=0
$$

Các phương trình động lượng Reynolds:

$$
\begin{aligned}
& \frac{\partial u}{\partial t}+\vec{v} . \nabla u+w \frac{\partial u}{\partial z}-f v=-\frac{\partial \varphi}{\partial x}+F_{u}+D_{u} \\
& \frac{\partial v}{\partial t}+\vec{v} . \nabla v+w \frac{\partial v}{\partial z}+f u=-\frac{\partial \varphi}{\partial y}+F_{v}+D_{v}
\end{aligned}
$$

Phương trình động lượng theo phương thẳng đứng: $\frac{\partial \varphi}{\partial z}=-\frac{\rho g}{\rho_{0}}$

Phương trình trạng thái $\rho=\rho(S, T, P)$ và giả thiết thủy tĩnh: $\frac{\partial P}{\partial z}=\rho g$

Các phương trình khuyếch tán nhiệt muối:

$$
\begin{aligned}
& \frac{\partial T}{\partial t}+\vec{v} \cdot \nabla T=F_{T}+D_{T} \\
& \frac{\partial S}{\partial t}+\vec{v} . \nabla S=F_{S}+D_{S}
\end{aligned}
$$

Trong đó: $u, v, w$ các thành phần vận tốc theo trục $\mathrm{x}, \mathrm{y}, \mathrm{z}$ trong hệ toạ đô Đề Các; $f$ : tham số Coriolis; $\mathrm{T}$ : nhiệt độ, $\mathrm{S}$ : độ muối, $\frac{\partial \varphi}{\partial x}=\frac{1}{\rho_{0}} \frac{\partial P}{\partial x}$ và $\frac{\partial \varphi}{\partial y}=\frac{1}{\rho_{0}} \frac{\partial P}{\partial y} ; D_{u}=\frac{\partial}{\partial z}\left(K_{M} \frac{\partial u}{\partial z}\right)$ và $D_{v}=\frac{\partial}{\partial z}\left(K_{M} \frac{\partial v}{\partial z}\right)$ là các thành phần nhớt và khuếch tán rối theo phương thẳng đứng.

Hệ phương trình cơ bản của ROMS viết trong tọa độ Sigma, tọa độ cong trực giao và các kí hiệu tham khảo trong tài liệu tiếng Việt [1] và tiếng Anh.

ROMS sử dụng lưới cong trực giao [7], do vậy miền tính có thể là miền cong bất kỳ và hệ toạ độ tương thích với địa hình theo phương thẳng đứng là hệ tọa độ Sigma $(\sigma$ hoặc $\mathrm{s}$, xem trong [4]). Vùng nghiên cứu là vùng biển Nam Bộ (Việt Nam) và toàn bộ vịnh Thái Lan (hình 1).

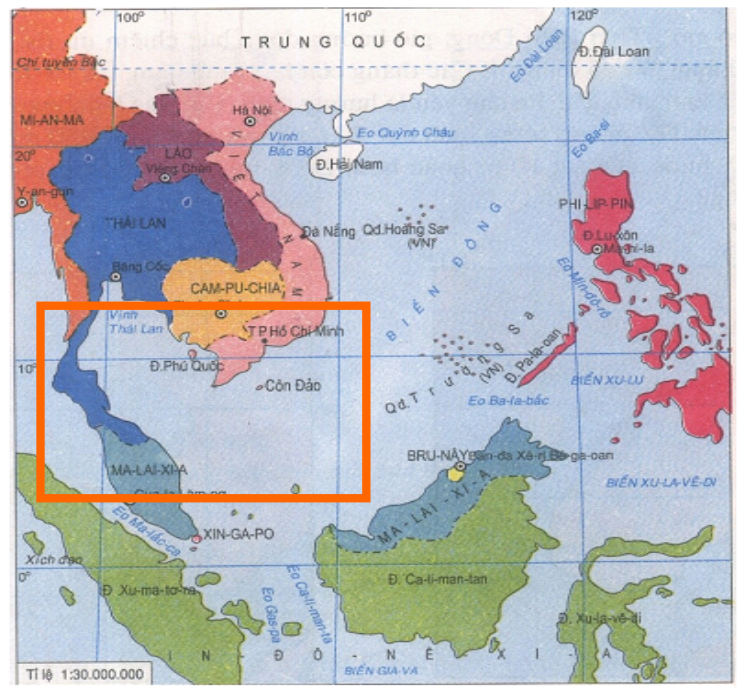

Hình 1. Sơ đồ vị trí vùng nghiên cứu

Đường bờ được lấy từ số liệu đường bờ của NOAA có trên trang web http://www.ngdc.noaa.gov/coast/getcoast.html

Địa hình vùng nghiên cứu được lấy từ số liệu phân tích ETOPO2 (NGDC, 1988) và có hiệu chỉnh thêm với các số liệu đo độ sâu thực tế ở vùng nghiên cứu.

Vùng nghiên cứu được phủ kín bởi một mạng lưới $90 \times 100$ điểm (hình 2) theo phương nằm ngang và 5 lớp sigma theo phương thẳng đứng với $\Delta x \approx 8-24,5 \mathrm{~km}, \Delta y \approx 2-16 \mathrm{~km}$, $\Delta z \approx 1 \div 400 \mathrm{~m}$ và bước thời gian $\Delta t=30 \mathrm{~s}$ là phù hợp với mô hình.

Thông lượng, nhiệt, bay hơi, mưa, gió, sức căng bề mặt biển theo mùa được lấy từ $\mathrm{COAD}$ [5]. Gió ven biển là rất khác nhau, rất khó để đo lường từ xa, sử dụng số liệu gió thông qua mô hình khí quyển (COAMPS) và từ truyền hình vệ tinh scatterometers (QuikSCAT) [3]. Các điều kiện biên mở phía Bắc, phía Đông và phía Nam mở là sự kết hợp giữa các thành phần bình lưu phản xạ bên ngoài [6], các điều kiện này được tính bằng cách sử dụng các dữ liệu khí tượng. 


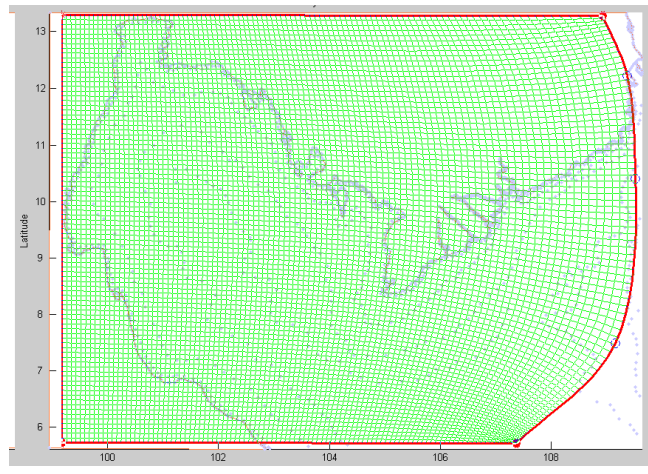

Hình 2. Mạng lưới cho vùng tính

Đối với thủy triều chúng tôi sử dụng dữ liệu từ TOPEX / Poseidon toàn cầu phiên bản 7.1
(TPXO7.1), nó là một mô hình thủy triều đại dương toàn cầu, phù hợp tốt nhất khi thực hiện trong một miền hình vuông.

Biên lỏng hướng sông được xác định qua lưu lượng và mặt cắt ướt của các cửa sông Mê Kông và sông Chao Phraya (Thái Lan). Trong mô hình chúng tôi sử dụng lưu lượng nước trung bình tháng của một số trạm thuỷ văn trên sông Mê Kông (http://www.mrcmekong.org, www.tiengiang.gov.vn) và sông Chao Phraya (lấy tì̀ http://webworld.unesco.org/water/ihp/db/shiklomanov/part\%274/ASIA/Thailand/2TH \%60Chao\%20Phraya\%20at\%20NakhonSawan .htm). Số liệu về lưu lượng bình quân tháng tại các trạm thuỷ văn như trong bảng 1 .

Bảng 1. Bảng lưu lượng $\left(\mathrm{m}^{3} / \mathrm{s}\right)$ trung bình tháng của sông Mê Kông và sông Chao Phraya.

\begin{tabular}{|c|c|c|c|c|c|c|c|c|c|c|c|c|}
\hline $\begin{array}{l}\text { Tháng } \\
\text { Trạm }\end{array}$ & $I$ & II & III & IV & $V$ & $V I$ & VII & VIII & $I X$ & $x$ & $X I$ & $X I I$ \\
\hline Sông Tiền & 3.700 & 2.650 & 1.910 & 1.380 & 2.400 & 5.380 & 9.880 & 11.400 & 16.400 & 21.200 & 5.800 & 9.430 \\
\hline Trị An & 800 & 650 & 500 & 350 & 350 & 500 & 800 & 850 & 900 & 990 & 900 & 850 \\
\hline Dầu Tiếng & 100 & 70 & 50 & 30 & 30 & 40 & 50 & 80 & 90 & 120 & 90 & 80 \\
\hline $\begin{array}{l}\text { Vàm Cỏ } \\
\text { Tây }\end{array}$ & 150 & 70 & 50 & 40 & 30 & 50 & 90 & 150 & 250 & 300 & 200 & 180 \\
\hline $\begin{array}{l}\text { Chao } \\
\text { Phraya }\end{array}$ & 279 & 309 & 362 & 386 & 421 & 531 & 624 & 936 & 1.569 & 1.913 & 1.129 & 512 \\
\hline
\end{tabular}

\section{KẾT QUẢ NGHIÊN CỨU}

Nghiên cứu hoàn lưu dòng chảy trong vùng biển Nam Bộ - vịnh Thái Lan bằng mô hình ROMS, mô phỏng trường dòng chảy trong thời gian dài theo mùa, mùa mưa (mùa gió Tây Nam) và mùa khô (mùa gió Đông Bắc), dữ liệu được xuất ra liên tục cho từng giờ (từ 0 giờ ngày $1 / 1 / 2009-31 / 12 / 2010)$. Các kết quả tính toán được thể hiện qua bản đồ phân bố trường vector dòng chảy cho phép nhận định các kêt quả tính toán có các đặc điểm như sau:

\section{Ảnh hưởng của ngoại lực lên trường dòng chảy}

Tại tầng mặt: trường dòng chảy thể hiện rõ được các vùng bị ảnh hưởng mạnh bởi các lực tác dụng. Như vùng chịu ảnh hưởng mạnh của nước sông Mê Kông đổ ra (vùng gần cửa sông), vùng nước chịu sự chi phối mạnh mẽ bởi trường gió (ngoài khơi Biển Đông), vùng chịu tác động mạnh mẽ bởi sự lên xuông của thủy triều như ở cửa, trong vịnh Thái Lan và vùng bị ảnh hưởng của đường bờ tới hoàn lưu dòng chảy tại đây (hình 3-5).

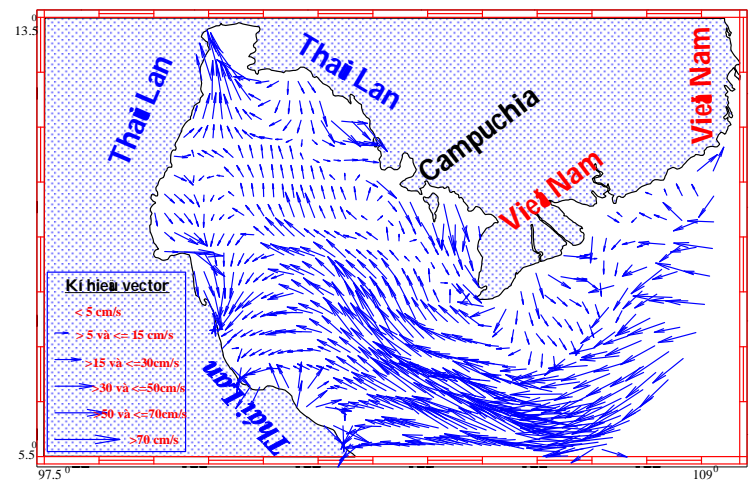

Hình 3. Phân bố trường dòng chảy tầng mặt vào một thời điểm của tháng $1 / 2009$ 

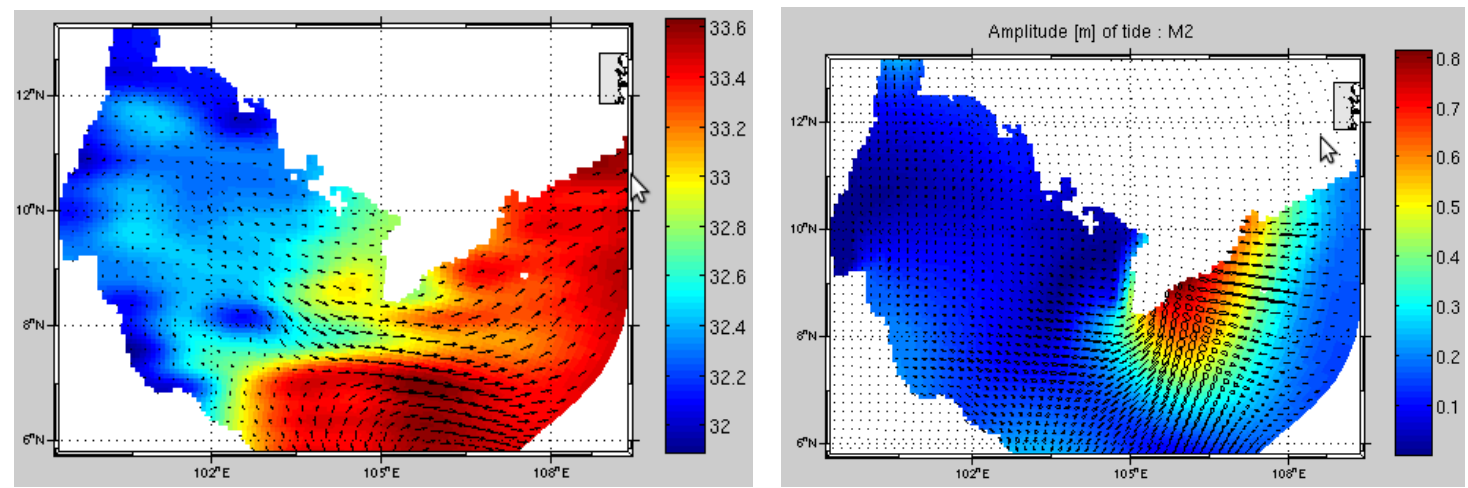

Hình 4. Phân bố độ muối và trường gió (trái) và phân bố biên độ sóng thành phần M2 (phải) vào tháng $7 / 2009$

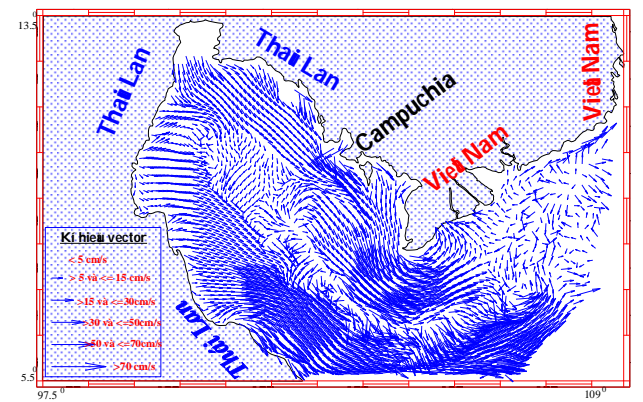

Hình 5. Phân bố trường dòng chảy tầng mặt vào một thời điểm của tháng 7-2009

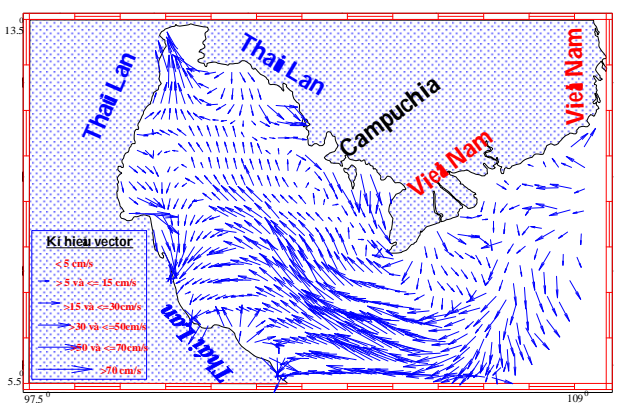

Hình 6. Phân bố trường dòng chảy tầng giữa vào một thời điểm của tháng $1 / 2009$

Ở tầng giữa (hình 6,7 ) và tầng đáy (hình 8 , 9), phân bô trường dòng chảy cho thấy hoàn lưu ở các tầng chịu tác động của các lực ngoài ít hơn nhất là tầng đáy tác động của trường gió tỏ ra mờ nhạt chỉ còn chịu ảnh hưởng mạnh của nước sông, thủy triều và ma sát đáy. Đặc điểm chung của hình thái dòng chảy ở tất cả các lớp là trường dòng chảy phân ra thành các khu vực có hướng và tốc độ khác. Tuy nhiên hướng ở các vùng khác nhau trong mỗi tầng đều có $\mathrm{xu}$ thế khác nhau. Ở vịnh Thái Lan, tại nhiều thời điểm trường vector dòng chảy có xu thế chung tại các lớp, trường dòng có hướng từ ngoài khơi vào bờ, tuy nhiên trường dòng chảy giữa lớp trên và lớp dưới có sự lệch nhau về hướng. Nét nổi bật của trường dòng chảy ở vùng biển Nam Bộ (Bình Thuận - Cà Mau) là xuất hiện dòng chảy Bắc - Nam mạnh vào mùa khô và dòng chảy ngược lại nhưng yếu hơn và thời gian xuất hiện ít hơn vào mùa mưa.

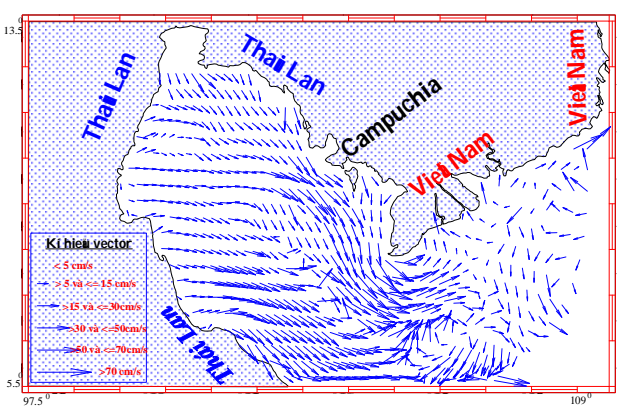

Hình 7. Phân bố trường dòng chảy tầng giữa vào một thời điểm của tháng 7/2009

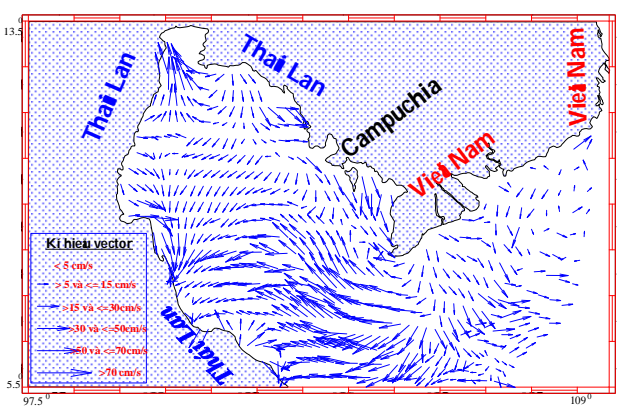

Hình 8. Phân bố trường dòng chảy tầng đáy vào một thời điểm của tháng $1 / 2009$ 


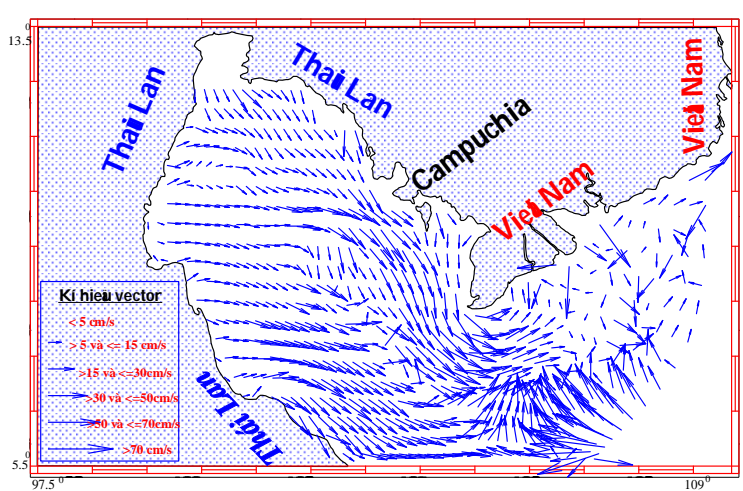

Hình 9. Phân bố trường dòng chảy tầng đáy vào một thời điểm của tháng 7/2009

\section{Sự hình thành và phát triển vùng xoáy trong vịnh Thái Lan:}

Vùng nước trong vịnh Thái Lan có tọa độ khoảng $101^{0}-104^{\circ} \mathrm{E}, 8,5^{0}-10^{0} \mathrm{~N}$ (hình 10) thường hay xuất hiện khu vực nước xoáy được hình thành và phát triển bởi chế độ thủy động lực phức tạp và địa hình đường bờ vịnh tạo nên. Quá trình hình thành khu vực nước xoáy này có thể được lý giải như sau:
Do bởi địa hình bờ vịnh Thái Lan có mũi Cà Mau (Việt Nam) tạo cho đường bờ phía Bắc vịnh có hình dạng cong lõm về phía bắc. Dòng nước chảy ven theo mũi Cà Mau chảy vào vịnh gây áp lực đẩy dòng nước chảy ven bờ phía Bắc lệch hướng chảy ra giữa vịnh. Dòng nước này cũng có tác động lại với dòng nước từ mũi Cà Mau vào làm cả hai dòng nước này phần lớn nước chảy ra giữa vịnh, phần nhỏ hơn chảy vào bờ. Dòng nước chảy ra giữa vịnh lại chịu tác động của dòng chảy ven bờ phía Nam vịnh tác động làm cho dòng này một phần lệch hướng dần có xu hướng chảy lên đỉnh vịnh. Hình dạng phần trên của vịnh Thái Lan gần như là nửa hình tròn do vậy nước bị hút nước mạnh hình thành dòng chảy vào vịnh men theo đường bờ cong tròn của vịnh Thái Lan có dạng một luồng dòng chảy cong từ Tây sang đông. Chu trình này tiếp tục cho đến khi dòng nước ven bờ từ mũi Cà Mau mạnh chiếm ưu thế tuyệt đối hoặc yếu thế bị dòng ven bờ phía Bắc lấn át.

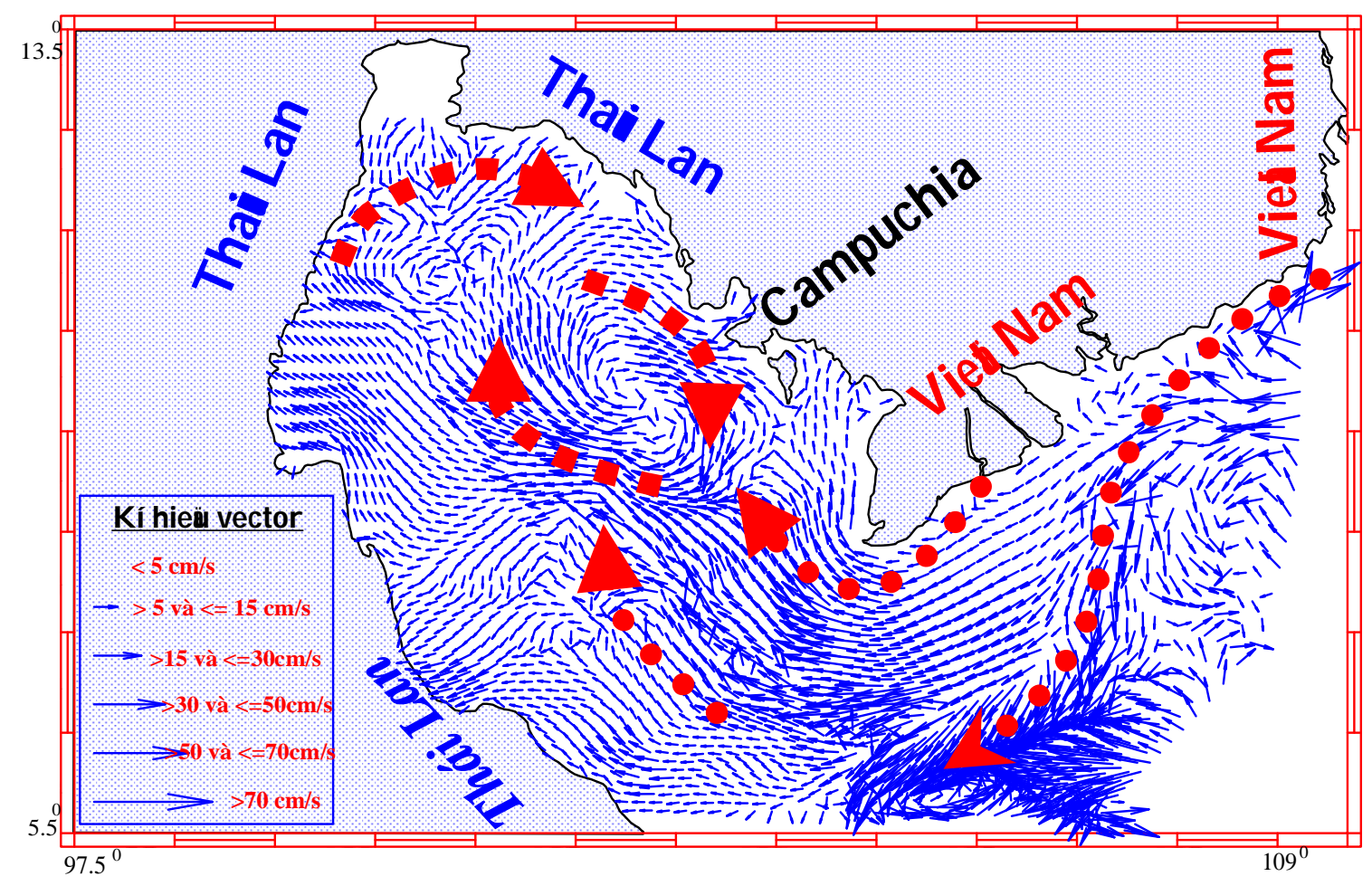

Hình 10. Sơ đồ hình thành vùng xoáy trong vịnh Thái Lan 
Các đặc điểm giống nhau và khác nhau của trường dòng chảy trong mùa mưa và mùa khô

\section{Giống nhau}

Trường dòng chảy ở nhiều thời điểm khác nhau tạo nên bởi các trường gió Đông Bắc (mùa khô) và trường gió Tây Nam (mùa mura) có thể tạo ra khu vực xoáy trong vịnh Thái Lan.

Hầu hết các trường véc tơ dòng chảy vào nhiều thời điểm của tât cả các trường gió đều thấy có dòng ven bờ trong vùng nghiên cứu, tuy nhiên tốc độ dòng mạnh yếu khác nhau tùy theo mùa.

Trường các vector dòng chảy của vùng nghiên cứu luôn phân chia thành các khu vực rõ rệt có hướng dòng rất khác nhau và tốc độ cũng khác biệt nhau.

\section{Khác nhau}

Nhìn chung, trong mùa khác nhau trường dòng chảy của vùng nghiên cứu mang tính đặc trưng riêng cho từng mùa:

Tốc độ dòng chảy vào mùa mưa tại vùng cửa sông Mê Kông có tốc độ dòng lớn hơn rât nhiều (cực đại khoảng $300 \mathrm{~cm} / \mathrm{s}$ ) so với tốc độ dòng chảy tại đó vào mùa khô (tốc độ cực đại khoảng $100 \mathrm{~cm} / \mathrm{s}$ ).

Vào mùa mưa, khu vực xoáy trong vịnh Thái Lan thường xuất hiện nhiều hơn và mạnh hơn vào mùa khô.

Vị trí dòng chảy ven bờ (Bắc - Nam) trong mùa mưa xa bờ hơn dòng chảy ven bờ (Nam lên Bắc) vào mùa khô.

\section{Kiểm chứng}

Với dao động mục nước biển

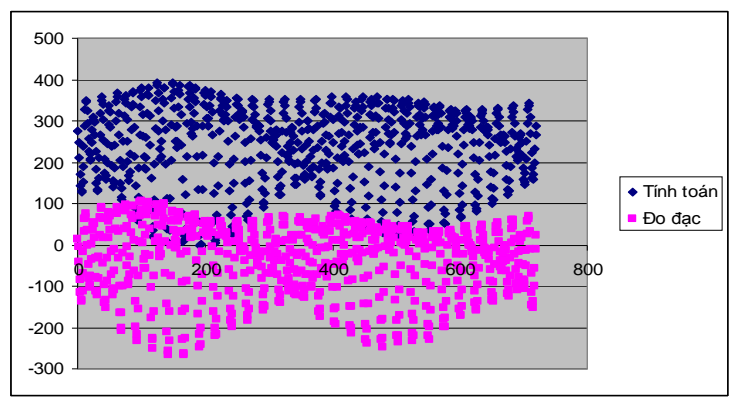

Hình 11. So sánh dao động mực nước giữa đo đạc (dưới) và tính toán (trên)
Kiểm chứng mô hình với số liệu đo đạc thực tế trong vùng. Số liệu để kiểm chứng lại mổ hình chúng tôi đã tiến hành thu thập số liệu dao động mực nước tại vùng Vũng Tàu (Việt Nam), các kết quả so sánh cho thấy mô hình cho kết quả dao động mực nước không quá khác biệt với thực đo (hình 11).

\section{Vói số liệu đo đạc dài ngày về dòng chảy}

Theo số liệu đo đạc về dòng chảy mới đây của Viện Hải dương học được thực hiện ở vùng cửa sông Mê Kông vào tháng tháng 8/2009 (từ 24 - 29/8/2009) và số liệu tính toán lấy ra tại tầng giữa của điểm tương ứng với trạm thực đo liên tục 7 ngày đêm, kết quảgiữa đo đạc và tính toán không quá khác biệt (hình 12).
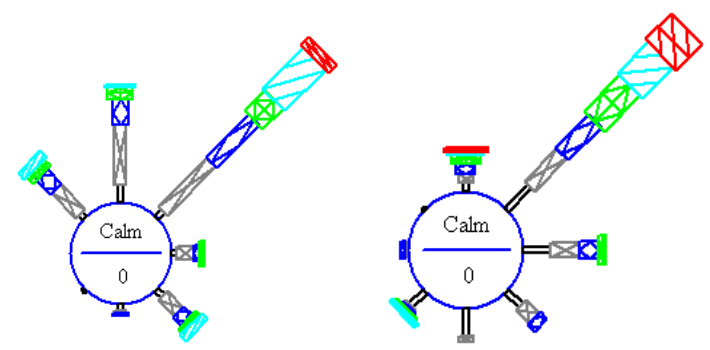

Hình 12. So sánh tần suất xuất hiện dòng chảy giữa đo đạc (trái) và tính toán (phải)

\section{KẾT LUẬN VÀ KIẾN NGH!}

Vào mùa gió Đông Bắc, vùng biển Nam Bộ xuất hiện dòng chảy dọc bờ (hướng Đông Bắc xuống Tây Nam) đổ nước vào vịnh Thái Lan đẩy dòng chảy ven bờ ở đây ra giữa vịnh và tạo thành khu vực xoáy ở vùng từ vĩ độ $9^{0}$ trở lên. Ở mùa gió Tây Nam, hiện tượng này cũng xuất hiện nhưng với tần xuất thấp và ngược hướng dòng chảy trong mùa gió Đông Bắc.

Các kết quả tính toán cho vùng biển Nam Bộ - vịnh Thái Lan nhìn chung là hợp lý về mặt định tính và đã góp phần phản ánh được phần nào bức tranh chung về hệ dòng chảy ở vùng biển này.

Số liệu đo đạc ở vùng nghiên cứu chưa có nhiều và không đồng bộ cho nên việc sử dụng số liệu này làm đầu vào hết sức hạn chế và dùng số liệu đo để hiệu chỉnh và kiểm định mô hình cũng rất khó khăn, cho nên các kết quả còn chưa thật phù hợp với diễn biến thực tế. Vì 
vậy, nghiên cứu sâu hơn nữa chế độ động lực trong vùng nghiên cứu cần có số liệu đo đạc chi tiết, đầy đủ đủ hơn để cho mô hình sử dụng cho kết quả tốt nhất.

\section{TÀI LIỆU THAM KHẢO}

1. Phạm Xuân Duoong, 2012. "Nghiên cứu hoàn lưu vùng vịnh Bình Cang - Nha Trang bằng mô hình số trị”. Luận án tiến sĩ địa lý, Viện khoa học Khí tượng, Thủy văn và Môi trường, Hà Nội.

2. Phạm Văn Huấn, 1996. "Về cơ chế hình thành những hiện tượng thủy triều phức tạp và độc đáo ở biển Đông". Tạp chí Khoa học, Đại học Quốc gia Hà Nội, tập XII, số 1. Tr. 33-39.

3. Chao Y., Z., Li, J. C. Kindle, J. D. Paduan, and F. P. Chavez, 2003. A high - resolution surface vector wind product for coastal oceans: Blending satellite scatterometer measurements with regional mesoscale atmospheric model simulations, 2003: Geophys. Res. Lett., 30(1) 1013, doi:10.1029/2002GL015729, 2003

4. Coo. Mellor, G.L. and A.F. Blumberg, 1985. "Modeling Vertical and Horizontal
Viscosity and the Sigma rdinate System", Mon. Wea. Rev., 113, 1379-1383.

5. Da Silva, A., C. Young, and S. Levitus, 1994. Atlas of Surface Marine Data 1994, Vol. 1-5. NOAA Atlas NESDIS, 6-10. U.S. Gov. Printing Office, Wash., D.C.

6. Marchesiello, P., J. C. McWilliams, and A. Shchepetkin, 2001. Open boundary conditions for long-term integrations of regional oceanic models. Ocean Modelling, $3,1-20$.

7. Vreugdenhil, C. B., 1998. Numerical Methods for Shallow - Water Flow, Kluwer Academic Publishers, Netherlands.

8. Shchepetkin, A. F., and J. C. McWilliams, 2003a. A method for computing horizontal pressure-gradient force in an ocean model with a non-aligned vertical coordinate, Journal of Geophysical, 108, 3090, Doi: 10.1029/2001 JC0011049.

9. Shchepetkin, A., and J. C. McWilliams, 2003b. The Regional Oceanic Modeling System: A split-explicit, free-surface, topography-following-coordinate ocean model, Journal of Geophysical, 108, 3268, doi: 10.1029/2002 JC001443. 
Mô phỏng hệ dòng chảy vùng biển Nam Bộ ...

\title{
MODELING CURRENT SYSTEM IN SOUTH VIET NAM WATERS- GULF OF THAILAND
}

\section{Pham Xuan Duong}

Institute of Oceanography-VAST

\begin{abstract}
This paper presents some results of the study on circulation regime of the South Vietnam waters-Gulf of Thailand during northeast monsoon (dry season) and southwest monsoon (rainy season) by ROMS model. Parameters of meteorological, tide, radiation, evaporation were taken from the global ocean data (resolution of $1 / 4$ degrees). The study results showed that during northeast monsoon, it's appeared the currents along the coast of South Vietnam waters from northeast to southwest. They pour into the Gulf of Thailand with high frequencies, and push the coastal flows into the middle areas of Gulf. By this aspect, the flow field in the Gulf of Thailand forms a closed cycle in the upper area from latitude $9^{\circ} \mathrm{N}$ at many moments. During the southwest monsoon, this phenomenon is also appears, but lower frequency, and the direction of flow from southwest to northeast.
\end{abstract}

Keywords: current system, northeast monsoon, southwest monsoon, closed cycle. 